\title{
Spectrophotometric Study of Complexation Between Some Salen Type Schiff Bases and Dimethyltin(IV) Dichloride
}

\author{
ALI HOSSEIN KIANFAR ${ }^{* a}$ and ISLAM ABROSHAN ${ }^{b}$

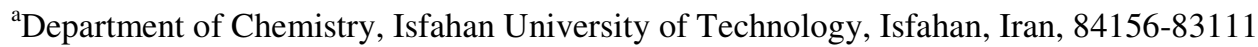 \\ ${ }^{\mathrm{b}}$ Department of Chemistry, Yasouj University, Yasouj, Iran \\ akianfar@cc.iut.ac.ir
}

Received 28 May 2012 / Accepted 14 June 2012

\begin{abstract}
UV-Vis spectrophotometric study of the complex formation of Salen type Schiff bases as donors with $\mathrm{Me}_{2} \mathrm{SnCl}_{2}$ as an acceptor have been investigated in chloroform. The formation constants were measured using UV-Vis spectrophotometric titration for 1:1 complex formation and by Ketelaar equation in the range $15-30{ }^{\circ} \mathrm{C}$. Thermodynamic parameters were determined by using Von't Hoff equation. The formation constant of the Schiff bases with dimethyletin(IV) dichloride in chloroform decreases according to the following trend: 3 - MeOSalen $>4$ - MeOSalen $>5$ - MeOSalen $\approx$ Salen $>5$ BrSalen and $\mathrm{Me}_{2}$ Salen $>$ Salbn $\approx$ Salpn $>$ Salen $>$ Salophen
\end{abstract}

Keywords: Schiff base, Dimethyltin dichloride, Formation constant, Complex formation

\section{Introduction}

Salen type of Schiff bases have been used as ligands, can coordinated to transition ${ }^{1,2}$ and main group ${ }^{3-7}$ metals. Several investigations have been done on the synthesis and molecular structure of tin Salen Schiff base complexes ${ }^{4,8-9}$. They are synthesized in specific conditions (for example in presence of a proton capture like triethylamine). Investigations show that, the organotin(IV) halides are in equilibrium with the porphyrins ${ }^{10-14}$. The metals Schiff base complexes react with organotin(IV) halides in an equilibrium condition ${ }^{15-17}$. On the other hand, there is a little evidence about equilibrium reactions between organotin(IV) halides with Salen Schiff base ligand ${ }^{18}$.

The present study describes the complex formation of dimethyltin(IV) dichloride with Salen type $\mathrm{N}_{2} \mathrm{O}_{2}$ Schiff base ligands, in which the Schiff bases have been used as a neutral tetradentate ligand through its $\mathrm{O}$ or $\mathrm{N}$ atoms. This paper describes spectral and thermodynamic studies of novel 1:1 complex formation dimethyltin(IV) dichloride as acceptor with Salen type Schiff base ligands such as Salen, 3-MeOSalen, 4-MeOSalen, 5-MeOSalen, 5-BrSalen, $\mathrm{Me}_{2}$ Salen, Salpn, Salbn and Salophen, as donor ligands in chloroform solvent (Figure 1). By comparing the spectral and the thermodynamic properties of Schiff base ligands, we aimed to investigate the effects of different electronic and steric behaviors. 


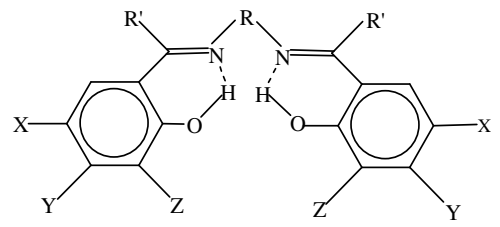

\begin{tabular}{cccccc}
\hline & $\mathrm{R}^{\prime}$ & $\mathrm{R}$ & $\mathrm{X}$ & $\mathrm{Y}$ & $\mathrm{Z}$ \\
\hline Salen & $\left(\mathrm{CH}_{2}\right)_{2}$ & $\mathrm{H}$ & $\mathrm{H}$ & $\mathrm{H}$ & $\mathrm{H}$ \\
Salpn & $\left(\mathrm{CH}_{2}\right)_{3}$ & $\mathrm{H}$ & $\mathrm{H}$ & $\mathrm{H}$ & $\mathrm{H}$ \\
Salbn & $\left(\mathrm{CH}_{2}\right)_{4}$ & $\mathrm{H}$ & $\mathrm{H}$ & $\mathrm{H}$ & $\mathrm{H}$ \\
Salophen & $\mathrm{C}_{6} \mathrm{H}_{6}$ & $\mathrm{H}$ & $\mathrm{H}$ & $\mathrm{H}$ & $\mathrm{H}$ \\
3-MeOSalen & $\left(\mathrm{CH}_{2}\right)_{2}$ & $\mathrm{H}$ & $\mathrm{H}$ & $\mathrm{H}$ & $\mathrm{MeO}$ \\
4-MeOSalen & $\left(\mathrm{CH}_{2}\right)_{2}$ & $\mathrm{H}$ & $\mathrm{H}$ & $\mathrm{MeO}$ & $\mathrm{H}$ \\
5-MeOSalen & $\left(\mathrm{CH}_{2}\right)_{2}$ & $\mathrm{H}$ & $\mathrm{MeO}$ & $\mathrm{H}$ & $\mathrm{H}$ \\
5-BrOSalen & $\left(\mathrm{CH}_{2}\right)_{2}$ & $\mathrm{H}$ & $\mathrm{Br}$ & $\mathrm{H}$ & $\mathrm{H}$ \\
Me Salen & $\left(\mathrm{CH}_{2}\right)_{2}$ & $\mathrm{CH}_{3}$ & $\mathrm{H}$ & $\mathrm{H}$ & $\mathrm{H}$ \\
\hline
\end{tabular}

Figure 1. The structure of Schiff bases used in this research

\section{Experimental}

Salicylaldehyde, 2-hydroxyacetophenone, 5-mehtoxysalicylaldehyde, 4-methoxysalicylaldehyde, 3-methoxysalicylaldehyde, 5-bromosalicylaldehyde, 1,2-ethylendiamine, 1,3-propanediamine, 1,4-butanediamine, dimethyltin dichloride, methanol ethanol and chloroform were purchased from Merck, Fluka or Aldrich.

\section{Physical measurement}

UV-Vis measurements were carried out in a JASCO V-570 UV-Vis spectrophotometer equipped with a LAUDA ecoline RE 104 thermostat. IR spectra were recorded by Shimadzu FTIR 8300 infrared spectrophotometer.

\section{Synthesis of Schiff base ligands}

The Schiff base ligands used in this study were prepared according to the literature methods ${ }^{19}$, by condensation of 1,2-diamines with aldehydes or ketoses (1:2 mole ratio) in methanol or ethanol and recrystalized by dichloromethane/methanol mixed solvent through the partial evaporation of dichloromethane.

\section{Equilibrium measurements}

The complex formations were obtained from the reaction of the acceptor with the donors according to Eq.(1):

$$
\mathrm{SB}+\mathrm{Me}_{2} \mathrm{SnCl}_{2} \rightleftarrows \mathrm{Me}_{2} \mathrm{SnCl}_{2}(\mathrm{SB})
$$

Where SB = Salen, Salpn, Salbn, $\mathrm{Me}_{2}$ salen, 3-MeOSalen, 4-MeOsalen, 5-MeOsalen, 5 -Brsalen and Salophen. The equilibrium constant measurements were carried out by spectrophotometric titration at $15,20,25$ and $30\left( \pm 0.1^{\circ} \mathrm{C}\right)$ in a typical measurement, $2.5 \mathrm{~mL}$ solution of Schiff base (about $2.5 \times 10^{-4}$ )) in chloroform was titrated with $\mathrm{Me}_{2} \mathrm{SnCl}_{2}$ (about $\left.3.6 \times 10^{-4}\right)$. The acceptor concentration varied from as much as 1 to 20 times in excess. UVVis spectra were recorded in the range of 300-500 $\mathrm{nm}$ about $5 \mathrm{~min}$ after each addition. The absorption measurements were monitored at various wavelengths in the range of 320-480 nm where the difference in absorption between the Schiff base substrate and the product was the largest after the equilibrium was attained. As an example, the variation of the electronic 
spectra for 3-MeoSalen, titrated with dimethyltin(IV) dichloride in chloroform is shown in Figure 2. The isosbestic points suggest that there are only two spices in equilibrium. The same is valid for the other systems.

\section{Results and Discussion}

\section{Spectrul characterization}

\section{Electronic spectra}

The electronic spectra of the Schiff base ligands in the solution phase show a relatively intense band in the 300-380 nm region, involving $\pi \rightarrow \pi^{*}$ transition and a low intensity $\mathrm{n}_{\mathrm{N}} \rightarrow$ $\pi^{*}$ excitation in the $360-500 \mathrm{~nm}$ region ${ }^{20}$.

Complex formation with dimethyltin(IV) dichloride results in two significant changes of the spectra took place in the UV-Vis region (250-500 nm) of $n \rightarrow \pi^{*}$ and $\pi \rightarrow \pi^{*}$ absorption bands upon this interaction. The original peaks of the Schiff base ligands changed and a new peak is appeared (Figure 2). By the adduct formation, the $n \rightarrow \pi^{*}$ transition disappears and a new intense band appears in this region $(350-500 \mathrm{~nm})$. It seems that this is an LMCT from $\mathrm{n}_{\mathrm{N}}$ to $\mathrm{Sn}(\mathrm{IV})$ via coordination of Schiff base ligand to dimethyltin dichloride. After coordination of Schiff base to $\mathrm{Me}_{2} \mathrm{SnCl}_{2}$, the $\pi \rightarrow \pi^{*}$ transition in $250 \mathrm{~nm}$ region has a red shift.

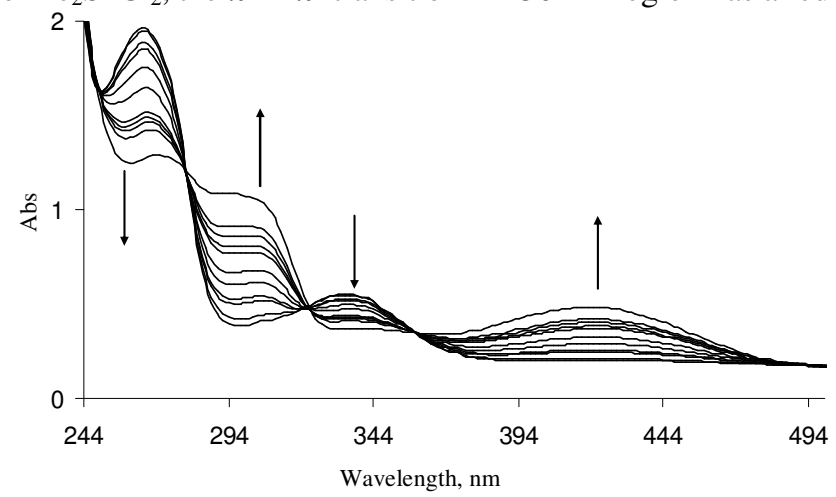

Figure 2. The variation of electronic spectra of 3-MeOSalen with dimethyltin(IV)dichloride in chloroform

The transition at about $300 \mathrm{~nm}$ has a different change via coordination to $\mathrm{Me}_{2} \mathrm{SnCl}_{2}$. While some complexes have no change in this transition, the others show red or blue shift. The clear isosbestic points in Figure 2 represent the complex formation in solution. Table 1 gives the original peaks of the Schiff bases and complexes produced by the addition of dimethyltin(IV) dichloride to Schiff base ligands.

\section{The formation constant and the thermodynamic free energy calculations}

With the goal of studding the effects of electronic and steric parameters of the Schiff bases on the formation constants and the thermodynamic free energy, the interaction of the Schiff base ligands as donors with $\mathrm{Me}_{2} \mathrm{SnCl}_{2}$ as acceptor were carried out. The formation constants of the various Schiff bases with dimethyltin(IV) dichloride were calculated using, Ketelaar equation $^{15-18,21}$.

The linear plots for $\mathrm{Me}_{2}$ Salen Schiff base titrated with $\mathrm{Me}_{2} \mathrm{SnCl}_{2}$ at various temperatures in chloroform are shown in Figure 3, which signify that only a 1:1 adduct is formed. Similar plots are obtained for the other systems. 
Table 1. The $\lambda_{\max }(\varepsilon(\mathrm{L} / \mathrm{mol} . \mathrm{cm}))$ for Schiff bases and their adducts in chloroform.

\begin{tabular}{|c|c|c|c|}
\hline Compound & $\begin{array}{c}\lambda\left(\pi-\pi^{*}\right), \\
\varepsilon, \mathrm{L} \cdot \mathrm{mol}^{-1} \cdot \mathrm{cm}^{-1}\end{array}$ & $\lambda\left(\pi-\pi^{*}\right)$ & $\begin{array}{l}\lambda\left(\mathrm{n}-\pi^{*},\right. \\
\mathrm{LMCT})^{\mathrm{a}}\end{array}$ \\
\hline $\mathrm{SalenH}_{2}$ & $256(20490)$ & $318(10730)$ & $408(97)$ \\
\hline Salen. $\mathrm{Me}_{2} \mathrm{SnCl}_{2}$ & $260(19520)$ & $280(15480)$ & $380(6000)$ \\
\hline $\mathrm{SalpnH}_{2}$ & $256(20880)$ & $316(9350)$ & $404(170)$ \\
\hline Salpn. $\mathrm{Me}_{2} \mathrm{SnCl}_{2}$ & $280(17230)$ & $318(8420)$ & $380(3000)$ \\
\hline $\mathrm{SalbnH}_{2}$ & $254(18640)$ & $316(7950)$ & $392(240)$ \\
\hline Salbn. $\mathrm{Me}_{2} \mathrm{SnCl}_{2}$ & $275(15270)$ & $320(7800)$ & $390(4620)$ \\
\hline $\mathrm{Me}_{2}$ Salen & $254(11760)$ & $322(5390)$ & $400(250)$ \\
\hline $\mathrm{Me}_{2} \mathrm{Salen} \cdot \mathrm{Me}_{2} \mathrm{SnCl}_{2}$ & $265(10150)$ & $320(4100)$ & $384(3280)$ \\
\hline 3-MeOSalenH ${ }_{2}$ & $266(15060)$ & $322(3290)$ & $426(334)$ \\
\hline 3-MeOSalen. $\mathrm{Me}_{2} \mathrm{SnCl}_{2}$ & $275(10270)$ & $300(7140)$ & $420(1910)$ \\
\hline 4-MeOSalenH $\mathrm{H}_{2}$ & $276(5685)$ & $310(4380)$ & $388(2321)$ \\
\hline 4-MeOSalen. $\mathrm{Me}_{2} \mathrm{SnCl}_{2}$ & - & $320(4120)$ & $368(6648)$ \\
\hline 5-MeOSalenH ${ }_{2}$ & $258(13600)$ & $350(83900)$ & $436(74)$ \\
\hline 5-MeOSalen. $\mathrm{Me}_{2} \mathrm{SnCl}_{2}$ & $280(12500)$ & $360(9530)$ & $420(11950)$ \\
\hline 5-BrSalenH ${ }_{2}$ & $256(31270)$ & $332(15280)$ & $422(121)$ \\
\hline 5-BrSalen. $\mathrm{Me}_{2} \mathrm{SnCl}_{2}$ & $256(30420)$ & $332(13540)$ & $400(5190)$ \\
\hline SalophenH $_{2}$ & $270(7770)$ & $336(4300)$ & $456(57)$ \\
\hline Salophen. $\mathrm{Me}_{2} \mathrm{SnCl}_{2}$ & $270(7800)$ & $320(5150)$ & $412(4710)$ \\
\hline
\end{tabular}

a) $n-\pi^{*}$ is selected to Schiff base and LMCT is applied for the adducts

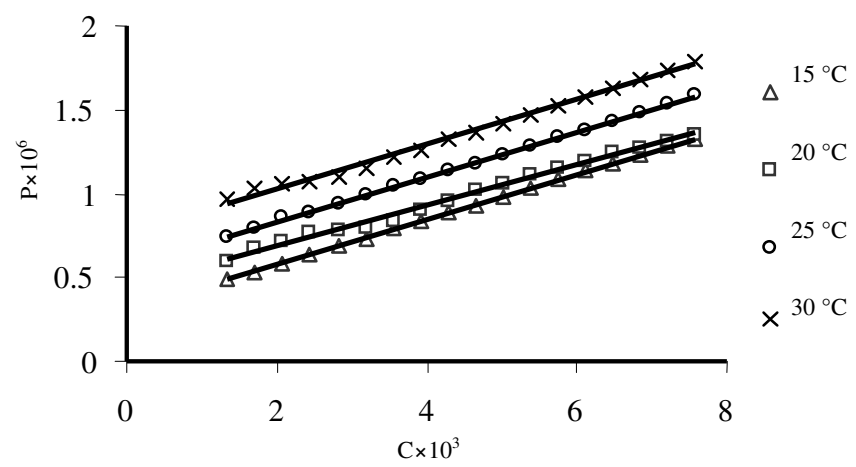

Figure 3. Plots of $\mathrm{P}$ vs. $\mathrm{C}$ for $\mathrm{Me}_{2} \mathrm{Salen}$ with dimethyltin(IV)dichloride in chloroform at various temperatures $\left(\mathrm{P}=\left(\mathrm{C}_{\mathrm{A}}^{\mathrm{O}} \mathrm{C}_{\mathrm{D}}^{\circ}\right) /\left(\mathrm{A}-\mathrm{A}_{\mathrm{A}}^{\circ}-\mathrm{A}_{\mathrm{D}}^{\circ}\right)\right.$ and $\left.\mathrm{C}=\left(\mathrm{C}_{\mathrm{A}+}^{\mathrm{O}} \mathrm{C}_{\mathrm{D}}^{\circ}\right)\right)$

The thermodynamic free energy, $\Delta \mathrm{G}$ and the thermodynamic parameters $(\Delta \mathrm{H}$ and $\Delta \mathrm{S})$ of the studied Schiff bases were obtained according to the literature ${ }^{15-18}$. The linear plots for $\operatorname{lnK}$ of Salbn titrated with $\mathrm{Me}_{2} \mathrm{SnCl}_{2}$ against 1/T are shown in Figure 4. The formation constants and the thermodynamic parameters for the selected Schiff bases toward $\mathrm{Me}_{2} \mathrm{SnCl}_{2}$ were collected in Tables 2 and 3 respectively.

\section{The steric effects of the Schiff base ligands}

For studying the steric effect of Schiff bases on the complex formation in solution, four Schiff bases with different diamine bridges (Salbn, Salpn, Salen and Salophen) were selected. On the bases of the results, the formation constants of complexes follow the sequence:

$$
\text { Salbn } \approx \text { Salpn }>\text { Salen }>\text { Salophen }
$$




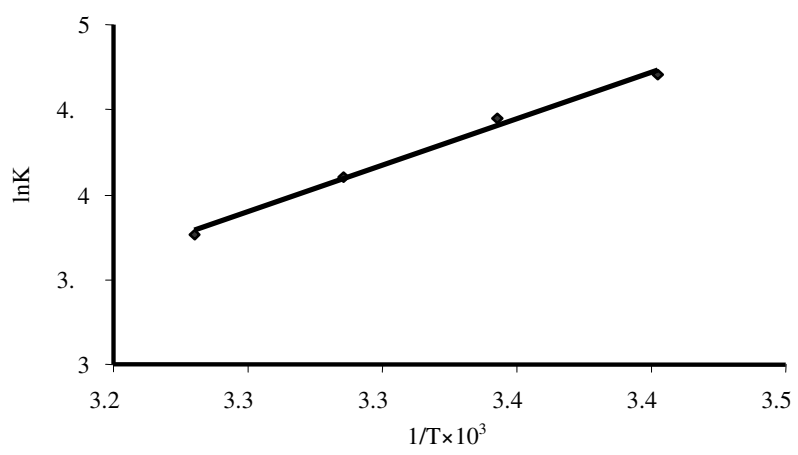

Figure 4. Plot of $\operatorname{lnK} v s .1 / \mathrm{T}$ for Salbn with dimethyltin(IV)dichloride in chloroform

Table 2. The formation constants, K $(\mathrm{L} \cdot \mathrm{mol})^{-1}$, for Schiff bases with dimethyltin(IV) dichloride in chloroform at various temperatures

\begin{tabular}{ccccc}
\hline Schiff Base & $15^{\circ} \mathrm{C}$ & $20^{\circ} \mathrm{C}$ & $25^{\circ} \mathrm{C}$ & $30^{\circ} \mathrm{C}$ \\
\hline $\mathrm{H}_{2}$ Salen & $(6.68 \pm 0.14) \times 10$ & $(6.13 \pm 0.14) \times 10$ & $(3.33 \pm 0.12) \times 10$ & $(2.56 \pm 0.08) \times 10$ \\
$\mathrm{H}_{2}$ Salpn & $(1.06 \pm 0.04) \times 10^{2}$ & $(6.89 \pm 0.14) \times 10$ & $(5.35 \pm 0.14) \times 10$ & $(3.51 \pm 0.12) \times 10$ \\
$\mathrm{H}_{2}$ Salbn & $(1.11 \pm 0.05) \times 10^{2}$ & $(8.55 \pm 0.16) \times 10$ & $(6.07 \pm 0.14) \times 10$ & $(4.32 \pm 0.13) \times 10$ \\
$\mathrm{Me}_{2}$ Salen & $(4.42 \pm 0.12) \times 10^{2}$ & $(2.71 \pm 0.08) \times 10^{2}$ & $(2.40 \pm 0.08) \times 10^{2}$ & $(1.75 \pm 0.04) \times 10^{2}$ \\
3-MeOSalen & $(1.87 \pm 0.06) \times 10^{3}$ & $(1.46 \pm 0.05) \times 10^{3}$ & $(1.30 \pm 0.06) \times 10^{3}$ & $(8.49 \pm 0.15) \times 10^{2}$ \\
4-MeOSalen & $(7.66 \pm 0.15) \times 10^{2}$ & $(5.27 \pm 0.13) \times 10^{2}$ & $(3.97 \pm 0.12) \times 10^{2}$ & $(3.15 \pm 0.11) \times 10^{2}$ \\
5-MeOSalen & $(6.78 \pm 0.14) \times 10$ & $(4.37 \pm 0.12) \times 10$ & $(2.79 \pm 0.08) \times 10$ & $(2.67 \pm 0.08) \times 10$ \\
5-BrSalen & $(4.17 \pm 0.12) \times 10$ & $(3.88 \pm 0.11) \times 10$ & $(3.06 \pm 0.11) \times 10$ & $(2.58 \pm 0.08) \times 10$ \\
Salophen & $(2.79 \pm 0.08) \times 10$ & $(3.25 \pm 0.10) \times 10$ & $(4.00 \pm 0.12) \times 10$ & $(4.37 \pm 0.12) \times 10$ \\
\hline
\end{tabular}

Table 3. The thermodynamic parameters, $\Delta \mathrm{G}(\mathrm{kJ} / \mathrm{mol}), \Delta \mathrm{H}(\mathrm{kJ} / \mathrm{mol})$ and $\Delta \mathrm{S}(\mathrm{J} / \mathrm{mol} . \mathrm{K})$ for Schiff bases with dimethyltin(IV)dichloride in chloroform

\begin{tabular}{cccc}
\hline Schiff Base & $\Delta \mathrm{G}(\mathrm{kJ} / \mathrm{mol})^{\mathrm{a}}$ & $\Delta \mathrm{H}(\mathrm{kJ} / \mathrm{mol})$ & $\Delta \mathrm{S}(\mathrm{J} / \mathrm{mol} . \mathrm{K})$ \\
\hline $\mathrm{H}_{2}$ Salen & $-(8.68 \pm 0.21)$ & $-(50.56 \pm 2.67)$ & $-(139.85 \pm 16.68)$ \\
$\mathrm{H}_{2}$ Salpn & $-(9.86 \pm 0.24)$ & $-(51.76 \pm 2.70)$ & $-(141.07 \pm 13.22)$ \\
$\mathrm{H}_{2}$ Salbun & $-(10.17 \pm 0.23)$ & $-(45.73 \pm 4.32)$ & $-(119.45 \pm 10.25)$ \\
$\mathrm{Me}_{2}$ Salen & $-(913.58 \pm 0.26)$ & $-(42.12 \pm 3.75)$ & $-(96.16 \pm 8.35)$ \\
3-MeOSalen & $-(17.76 \pm 0.37)$ & $-(36.08 \pm 2.55)$ & $-(62.42 \pm 4.28)$ \\
4-MeOSalen & $-(14.83 \pm 0.43)$ & $-(42.81 \pm 4.76$ & $-(93.69 \pm 9.53)$ \\
5-MeOSalen & $-(8.25 \pm 0.28)$ & $-(46.87 \pm 5.12)$ & $-(128.30 \pm 10.82)$ \\
5-BrSalen & $-(8.47 \pm 0.24)$ & $-(24.31 \pm 1.15)$ & $-(53.07 \pm 2.66)$ \\
Salophen & $-(9.14 \pm 0.32)$ & $+(22.56 \pm 1.87)$ & $+(106.12 \pm 5.28)$ \\
\hline
\end{tabular}

a) at $25^{\circ} \mathrm{C}$

As previously described, the complex formation increases when the steric hindrance of the Schiff base ligands increases ${ }^{17,22-23}$.

\section{The electronic effects of the Schiff base ligands}

The Salen, 5-Br Salen, 5-MeOSalen, 4-MeOSalen and 3-MeOSalen Schiff bases were selected (the electronic spectrum of 5- $\mathrm{NO}_{2} \mathrm{Salen}$ is no changed in the presence of $\mathrm{Me}_{2} \mathrm{SnCl}_{2}$ ) to study the electronic effect of the Schiff base ligands for interaction with $\mathrm{Me}_{2} \mathrm{SnCl}_{2}$. The results show the following trend in the complex formations between Schiff bases and dimethyltin dichloride (Table 2). 


\section{$5 \mathrm{MeOSalen} \approx$ Salen $>5$-BrSalen $>>5-\mathrm{NO}_{2}$ Salen (no reaction)}

The stability constants were changed as can be expected from the electronic effects of the substituent on para relative to phenolic oxygen. Thus, the stability constants decrease according to the sequence $\mathrm{MeO} \approx \mathrm{H}>\mathrm{Br}>>\mathrm{NO}_{2}$, i.e. in the order of an increase in electron withdrawing the substituents and the decrease in donor ability of the ligand groups.

The effect of functional groups on the Metal Schiff bases and their properties were investigated intensively. Similar results have been reported previously for electrochemical properties of the analogous $\mathrm{Cu}(\mathrm{II}), \mathrm{Ni}(\mathrm{II}), \mathrm{Co}(\mathrm{II})$ and $\mathrm{V}(\mathrm{IV})^{24-27}$. These results show that the oxidation and reduction potentials are proportional to donor or acceptor property of functional groups on para substitute to phenolic oxygen of Salen type Schiff base ligands.

Investigations on the interaction of metal Schiff base complexes (Ni(II) and $\mathrm{Cu}(\mathrm{II})$ ) with organotin halides show that the phenolic oxygen can be coordinated to $\mathrm{Sn}(\mathrm{IV})$ as an accepter center, in addition of metal ion. So the functional groups in para relative to this position can affect the interaction and the formation constants ${ }^{15}$. The reported results show that the formation constants decrease by increasing the electron withdrawing property of functional groups in para relative to phenolic oxygen. On the other hands, the results in this research are not ordered like the reported ones, but the formation constants are decreased by increasing the electron withdrawing of the functional groups. It seems that, the non linear relationship arises from the different mechanism of the interaction of Schiff base ligands with dimethyltin(IV) dichloride relative to metal Schiff base complexes, in which the functional groups in 5-X Salen ligands have an indirect effect on donor atoms toward acceptor.

To study the effect of the position of substituent on the complex formation, 3-MeO Salen, 4-MeOSalen and 5-MeOSalen were selected. The results show the following trend in the adduct formations between Schiff base ligands and $\mathrm{Me}_{2} \mathrm{SnCl}_{2}$ (Table 2).

$$
\text { 3-MeOSalen }>4 \text {-MeOSalen }>5 \text {-MeOSalen } \approx \text { Salen }
$$

On the bases of the molecular structure of $\mathrm{R}_{2} \mathrm{SnCl}_{2}$, $\mathrm{Ni}$ (Schiff base) adducts, in the case of $\mathrm{Ni}(3-\mathrm{MeOSalen})$, the phenolic oxygen donor atoms of $\mathrm{N}_{2} \mathrm{O}_{2}$ backbone and 3-MeO groups contribute to adducts formation ${ }^{15}$. With respect to the structural representation of Schiff base ligands (Figure 1), the methoxy groups of 4-MeOSalen are situated in the para position to the iminic nitrogen atoms. Therefore we believe that the Schiff base ligands are coordinated to $\mathrm{Me}_{2} \mathrm{SnCl}_{2}$ via nitrogen atoms. So the methoxy groups in the para relative to nitrogens increase the donating ability of Schiff base ligands toward $\mathrm{Me}_{2} \mathrm{SnCl}_{2}$, more than 5-MeOSalen.

This is a different mechanism for interaction of Schiff base ligands relative to metal Schiff base toward dimethyltin(IV) dichloride, in which the Schiff base nitrogens coordinate to $\mathrm{Me}_{2} \mathrm{SnCl}_{2}$. This mechanism shows that the functional groups in 5-XSalen have an indirect inductive effect on iminic nitrogen and show why the formation constants for 4-MeOSalen is more than those of the 5-MeOSalen. For more investigation about this mechanism, the $\mathrm{Me}_{2} \mathrm{Salen}$ with two methyl groups in iminic carbon was interacted with $\mathrm{Me}_{2} \mathrm{SnCl}_{2}$ and the results show (Table 2) that the formation constants decreased in the following trends:

$$
\mathrm{Me}_{2} \text { Salen }>\text { Salen }
$$

With respect to the structural representation of Schiff base ligands (Figure 1), the methyl groups were situated in iminic carbon that can act as an electro-donor group toward the iminic bond and increases the donor ability of Schiff base ligand. 
In contrast to the metal Schiff base complexes, it seems that in the 3-MeOSalen, the methoxy groups can contribute to the nitrogen atom via hydrogen bonding with phenolic hydrogens. The interaction of Schiff base ligands with $\mathrm{Me}_{2} \mathrm{SnCl}_{2}$ is within breaking of hydrogen bond that happens in 3-MeOSalen with contribution of methoxy groups in a better way.

\section{Thermodynamic parameters}

\section{The heat of formation}

The $\Delta \mathrm{H}$ value depends on the heat of complex formation and the salvation effect ${ }^{28}$. Schiff base ligands have internal hydrogen bonding according to the proposed mechanism and it is needed to break the hydrogen bonding via the complex formation. This factor has positive contribution to $\Delta \mathrm{H}$. The overall enthalpy values are negative (except for Salophen) and it is shown that the complex formation is more important to determine the $\Delta \mathrm{H}$ value.

The entropy values

The $\Delta S$ value and its sign also depend upon the different number of the particles of the initial substances and complex. The $\mathrm{n}$ is -1 for this study. Concerning this factor, $\Delta \mathrm{S}$ is negative. The second factor is the liberation of the solvent molecules from the solvation shells. This factor has positive contribution to $\Delta S^{28}$. The overall enthalpy values are negative (except for Salophen) and it is shown that the complex formation is more important to determine the $\Delta \mathrm{S}$ value.

\section{The effect of temperature on the complex formation}

The formation constants were carried out at various temperatures. In general, because of bond formation it is shown that by increasing the temperature the formation constants were decreased. But in the case of Salophen a reverse trend was seen. The results show that the geometry of Salophen probably changes to tetrahedral by increasing the temperature. The equilibrium of the planar and the tetrahedral form is temperature dependent and shifts toward the tetrahedral with increasing temperature ${ }^{29}$. The distortion of the planar to the tetrahedral geometry favored the complex formation ${ }^{30}$. It is shown that this form is a better ligand for coordination to dimethyltin dichloride. Therefore, the formation constants were increased by increasing the temperature for Salophen as a ligand toward $\mathrm{Me}_{2} \mathrm{SnCl}_{2}$ as acceptor.

\section{Conclusion}

By considering the formation constants and the $\Delta \mathrm{G}$ of the complex formation for Schiff bases as donor and the dimethyltin(IV)dichloride as acceptor, the following conclusions have been drawn:

1. The formation constant changes according to the following trend for Schiff bases due to the steric factor:

$$
\text { Salbn } \approx \text { Salpn }>\text { salen }>\text { Salophen }
$$

2. The formation constant changes according to the following trend for Schiff bases due to the electronic factor:

$$
\begin{gathered}
5 \mathrm{MeOSalen} \approx \text { Salen }>5 \text {-BrSalen }>>5-\mathrm{NO}_{2} \text { Salen (no reaction) } \\
3 \text {-MeOSalen }>4 \text {-MeOSalen }>5 \text {-MeOSalen }
\end{gathered}
$$

\section{Acknowledgment}

We are grateful to Yasouj University Research Council for their financial support. 


\section{References}

1. Holm R H, Everett G W and Chakra-vorty Jr A, Prog Inorg Chem., 1966, 7, 83.

2. Hobday M D and Smith T D, Coord Chem Rev., 1972, 9, 311.

3. Atwood D A and Harvey M J, Chem Rev., 2001, 101, 37; DOI: 10.1021/cr990008v

4. Agustin D, Rima G, Gornitzka H, Barrau J and Stable J, Organomet Chem., 1999, 592, 1-10.

5. Kutchta M C, Hahn J M and Parkin G, J Chem Soc., Dalton Trans., 1999, 3559.

6. Singh M S, Tawade K and Singh A K, Main Group Met Chem., 1999, 22, 175.

7. Hobday M and Smith T D, J Chem Soc., Sect A, 1971, 1453-1457.

8. Dey D K, Das M K and Noth H, Z Naturforsch., 1999, 54b, 145.

9. Atwood D A, Yearwood B and Parkin S, Inorg Chim Acta, 2002, 333, 124-131.

10. Asadi M, Zabardasti A and Ghasemi J, Polyhedron, 2002, 21(7), 683.

11. Asadi M, Zabardasti A and Ghasemi J, Bull Chem Soc Jpn., 2002, 75, 1137-1141.

12. Asadi M and Zabardasti A, J Chem Research (S), 2002, 611.

13. Zabardasti A, Asadi M and Kakanejadifard A, J Heterocyclic Chem., 2006, 43, 1157-1160.

14. Zabardasti A, Salehnassaje M, Asadi M and Karimivand V A, Polish J Chem., 2006, 80(9), 1473-1481.

15. Asadi M, Aein Jamshid Kh and Kyanfar A H, Inorg Chim Acta., 2006, 360, 1725-1730.

16. Asadi M, Aein Jamshid Kh and Kyanfar A H, Trans Met Chem., 2007, 32, 822-827.

17. Asadi M, Aein Jamshid Kh, Kyanfar A H, Synth React Inorg Met-Org Chem., 2007, 37(2), 77-83.

18. Asadi M, Aein Jamshid Kh and Kyanfar A H, J Coord Chem., 2008, 61, 1115-1126.

19. Hariharan M and Urbach F L, Inorg Chem., 1969, 8, 556-559.

20. Grawford M S, Spectrochim Acta, 1963, 19, 255-270.

21. Ketelaar J A A, Van De Stolpe C, Coulsmit A and Dzcubes W, Rec Trav Chim., 1952, 71, 1104-1114.

22. Carbonaro L, Isola M, Pegna P L, Senatore L and Marchetti F, Inorg Chem., 1999, 38, 5519-5525.

23. Inada Y, Mochizuki K, Tsuchiya T, Tsuji H and Fanahashi S, Inorg Chim Acta, 2005, 358, 3009-3014.

24. Jager E G, Schuhmann K and Gorls H, Inorg Chim Acta, 1997, 255(2), 295-305.

25. Sarvestani A H, Salimi A, Mohebbi S and Hallaj R, J Chem Res., 2005, 3, 190-193.

26. Sarvestani A H and Mohebbi S, J Chem Res., 2006, 4, 257-260.

27. Kianfar A H and Mohebbi S, J Iran Chem Soc., 2007, 4, 215-220.

28. Ahrland S, Helv Chim Acta, 1967, 50, 306.

29. Knoch R, Elias H and Paulus H, Inorg Chem., 1995, 34, 4032.

30. Taylor M. K, Reglinski J and Wallace D, Polyhedron, 2004, 23, 3201-3209. 